\title{
Canadian Nursing Students' Experiences with Medical Assistance in Dying / Les expériences d'étudiantes en sciences infirmières au regard de l'aide médicale à mourir
}

\author{
Cedar McMechan \\ University of Victoria, cedar.Imc@gmail.com
}

Anne Bruce

University of Victoria, abruce@uvic.ca

Rosanne Beuthin

Island Health, rosanne.beuthin@viha.ca

Follow this and additional works at: https://qane-afi.casn.ca/journal

Part of the Education Commons, and the Nursing Commons

\section{Recommended Citation}

McMechan, Cedar; Bruce, Anne; and Beuthin, Rosanne (2019) "Canadian Nursing Students' Experiences with Medical Assistance in Dying / Les expériences d'étudiantes en sciences infirmières au regard de l'aide médicale à mourir," Quality Advancement in Nursing Education - Avancées en formation infirmière: Vol. 5: Iss. 1, Article 2.

DOI: https://doi.org/10.17483/2368-6669.1179

This Article is brought to you for free and open access by Quality Advancement in Nursing Education - Avancées en formation infirmière. It has been accepted for inclusion in Quality Advancement in Nursing Education - Avancées en formation infirmière by an authorized editor of Quality Advancement in Nursing Education - Avancées en formation infirmière. 


\section{Canadian Nursing Students' Experiences with Medical Assistance in Dying / Les expériences d'étudiantes en sciences infirmières au regard de l'aide médicale à mourir}

\section{Cover Page Footnote}

Funding for this study was received from the Jamie Cassels Undergraduate Research Award (JCURA) and Island Health Authority. Le financement de cette étude provient du Jamie Cassels Undergraduate Research Award (JCURA) et du Island Health Authority. 
When asked why she wanted to be present during a medically assisted death, one student nurse replied:

I just wanted to know what it felt like to be present in that situation. I was pushing myself into a situation that I knew was going to be uncomfortable, as part of my own growth as a student. I knew from previous [clinical] experiences that having a first experience does facilitate further learning. You know, just like exercising a muscle, the more you stretch it, the more it hurts, the stronger it gets.

\section{Introduction}

In February 2015, the Supreme Court of Canada deemed the criminalization of physician assisted suicide to be a violation of the Canada's Charter of Rights of Freedoms. Subsequently, Bill C-14 was passed in June 2016, granting legal access to Medical Assistance in Dying (MAiD) for those meeting strict eligibility criteria (Bill C-14, 2016). Representing a new era in end-of-life care in Canada, MAiD has significant implications for health care workers, nurse educators, and society at large. Nursing students in their clinical placements may be asked to contribute directly or indirectly to a medically assisted death, requiring some to reconceptualize their professional role from promoting healing and prolonging life to also, conversely, expediting death. This development adds an ethical dimension to the already fragile and at times trying experience of student nurses witnessing death—often for the first time (Österlind et al., 2016).

MAiD remains a divisive issue. Those in support of this option argue that it respects the individual's right to bodily autonomy (Oliphant, 2017) and presents a means to a dignified death for those suffering intolerably (Attaran, 2015). In addition, those who support "the right to die" suggest MAiD holds potential to mitigate fear and isolation for those nearing death (Li et al., 2017). Others oppose MAiD on the premise that assisting in death violates the principle of sanctity of life (Singh, 2012) and argue for greater access to palliative care rather than a hastened death.

Little is known about nursing students' experiences with or attitudes toward MAiD in the Canadian context. Understanding students' perceptions and experiences at this early stage of implementing MAiD is important in order to develop effective educational approaches and student supports for this new practice. Additionally, providing a snapshot of students' perceptions at this historic time will enable nurse scholars to analyze the evolution of attitudes and experiences as MAiD becomes an established option in Canadian society.

\section{Literature Review}

No research was found addressing the experiences of nursing students with MAiD in Canada; however, students' experience of providing palliative and end-of-life care has been explored widely in several contexts. Previous findings have identified the emotional impact on students of providing care near death, including feelings of anxiety, stress, and impotence (Cooper \& Barnett, 2005; Edo-Gual, Tomás \& Sábado, Bardallo \& Porras, \& Monforte \& Royo, 2014; Leighton \& Dubas, 2009; Österlind et al., 2016). Care of dying patients requires students to attend to the physical, spiritual, and psychosocial needs of the patient and family, while undergoing their own learning experience with death. For some students, these demands highlight the limitations of their life (in)experience (Sampaio et al., 2015). While difficult, students' encounters with the dying are also reported as profound and gratifying (Edo-Gual et al., 
2014; Garrinno, Contratto, Massariello, \& Dimonte, 2017), and students make extra efforts to provide exceptional care to these patients (Ranse, Ranse, \& Pelkowitz, 2018).

\section{Study Purpose and Design}

The purpose of this study was to explore the experiences of senior nursing students in caring for patients who choose a medically assisted death. The study further aimed to understand students' perceptions of their educational preparation regarding MAiD and to identify potential gaps in existing knowledge and skills.

\section{Methodology}

A qualitative design drawing on narrative inquiry (Riessman, 2008) and thematic analysis (Braun \& Clarke, 2006) was used. Participants were recruited by email through a university student listserv and short class presentations by the student researcher (CM). All fourth-year students were invited to participate, totaling 166 student nurses. Ethics approval was granted by the university's Human Ethics Research Board.

Participants included nine fourth-year students in a Bachelor of Science in Nursing (BSN) program in a Canadian university. Participants' ages ranged from 22-54 years (mean=35). Eight students had at least one year of post-secondary education prior to beginning the BSN program. Two students were also practicing licensed practical nurses (LPNs) at the time of the interviews. When asked about religious affiliation, three participants identified as currently religious, one had no current affiliation but a "strong religious upbringing," and one was spiritual but not religious. Two described having no religious background or affiliation, and one participant declined to answer this question. Seven participants had some level of experience caring for a patient receiving MAID (under the supervision of a preceptor $\mathrm{RN}$ ), with one participant present during the MAiD procedure and death. No participants declined opportunities to participate in care of a patient receiving MAiD on the basis of personal beliefs or otherwise.

Data collection. Data were collected from December 2017 to January 2018 using audiotaped, semi-structured interviews conducted in-person or by phone. All interviews were conducted by one researcher, who was also a fourth-year student. Training in conducting qualitative interviews was provided by the co-investigators who have extensive experience in research. Interviews lasted approximately 35-50 minutes. Sample interview questions are listed below.

1. What is your perspective on the practice of MAiD? What experiences or aspects of your life have informed this perspective?

2. How has your experience in nursing school, through both theory and practice, shaped your views on MAiD? How, (or) has it changed over time?

3. Picture a future scenario in which you are a new graduate being asked to care for a patient receiving MAiD. How does this make you feel?

4. What kind of preparation do you feel you need to care for a patient accessing MAiD, if any?

5. If applicable, please tell me about your first experience of being asked to participate in a medically assisted death and how you came to the decision to participate or not participate. 
Rigour and reflexivity. Three researchers were involved in the analysis, thematic development, and final interpretation of results, allowing for diversified perspectives on findings. The first author worked in close consultation and collaboration with the co-investigators to understand and mitigate potential negative effects of being a peer researcher. All students were given the option to contact and be interviewed by either the student researcher or a coinvestigator to minimize potential peer dynamics including coercion. Field notes were generated to document impressions and facilitate reflexivity through the research process. Credibility was enhanced by asking participants to review preliminary findings and provide feedback.

Analysis. Thematic analysis was guided by Braun and Clarke (2006). Interviews were transcribed verbatim and then divided and read by the research team. Each member presented a summary of her assigned transcripts, followed by group discussion on impressions and emerging themes. Main codes were identified, and transcripts were coded for these preliminary topics. Final themes and subthemes were identified using inductive reasoning and sorted into four main themes and six subthemes.

\section{Results}

Results are organized into the four main themes: role confusion, honouring patient autonomy, personal-professional tensions, and students' recommendations for education. Each theme has corresponding subthemes as described below.

\section{Theme 1: Role Confusion}

Students expressed confusion and misconceptions about their role as nursing students and those of nurses more broadly in MAiD. They shared anecdotes of witnessing RNs and LPNs in practice who lacked knowledge of this practice. Two subthemes were identified, where do (student) nurses fit? and fear of saying the wrong thing.

Where do (student) nurses fit? Students commonly expressed confusion about their scope of practice in the process of MAiD, both as student nurses and future RNs. Three participants stated that as students, they thought they were not permitted to be present in the room during the actual death for legal reasons. Two students believed this restriction applied to RNs as well. Another believed she was not authorized to provide any care at all for a patient awaiting a medically assisted death. In the Provincial Health Authority in which these students practiced, both students and RNs are authorized to care for and be in room with a client receiving MAiD.

Deciphering where the students belonged in the context of MAiD was further complicated by their awareness of the intimacy of the dying process. Participants had a desire to be present during MAiD for the educational value of this exposure, but also remained dedicated to respecting patient and family privacy. Students described this tension as a dilemma between wanting to be present for learning purposes, but not feeling their presence was appropriate given the sensitive nature of dying. One participant stated:

I wanted to watch and witness and kind of be a part of [a medically assisted death] - to understand... but I didn't feel that it was appropriate because that was the day his family was coming. I didn't want to introduce a brand-new face and be like, hey I'm a student can I just stand in the corner? So I was really conflicted with... being presented with this learning opportunity but not being able to really take it because it just wasn't really fair. 
Another participant noted the following:

And I don't know -it's such an intimate final experience. It's not something that's suitable for a student to observe but I would have advocated if it was a patient of mine say that patient that I had been working with was going to have MAiD, I would have really tried to be there with her and her husband [during the MAiD].

For one student who was present during a MAiD death, this desire to not impose upon the family's emotional process was further evident:

I was standing very close to the door and against the wall to try and make myself as inconspicuous as I could, so not to interfere with the emotions of the family. I did ask them if they were okay with me being there but at the same time I didn't want to really be a presence; I wanted to let them be the presence in the room. So, there were a lot of tears but I was trying really hard to draw learning from the situation so I tried to not involve myself in the emotion of it as much as I could. I mean I'm sure I did cry during the process but quietly, to myself.

As evidenced by participant's anecdotes, students' perspectives were also mirrored in the uncertainty demonstrated by nurses on their clinical placement units. Participants felt that many nurses are "still in the dark" on the subject of MAiD. One student described this uncertainty during a clinical rotation on an acute medical floor: "I think there was a lot of misinformation; things that we didn't know like starting the IV, or who could care for whom ... It was still a blurry area-so everyone was still [wondering], ok, am I doing everything right?" Another student described a dilemma she witnessed when her supervising $\mathrm{RN}$ was asked to sign the MAiD consent form for a patient:

It was sort of the first [medically assisted death] on the floor and there was the question of should I sign this or should I not sign this [required witness form]? It was on a weekend so the clinical nurse educator wasn't available to ask questions. So, it was a question of "where do I go to get the resources" and I don't think that the training had been implemented yet. So nurses on the floor really didn't know what to do.

Fear of saying the wrong thing. Several student participants expressed concern about speaking with their patients about MAiD. Many stated that they understood it was beyond the scope of the nurse or nursing student to counsel patients about MAiD; however, few were certain about what this constraint meant in practice. Many participants expressed fear of broaching the subject of MAiD at all with their patients. "I would never present [MAiD] to somebody myself because I know that that's not within my scope of practice" said one participant. "I'm scared that I'm going to say something wrong," another student shared, "and then I'm on the chopping block for them asking me about MAiD."

Participants referred to how their awareness of not being allowed to speak with patients about MAiD was founded in their BSN education: "The message I got [in university] was do not open your mouth if the patient talks about it. You cannot speak to patients about this." While providing care for a patient awaiting MAiD, one student shared how her awareness of this lesson was ever-present. "I still had that niggling in the back of my mind that as students you're not allowed to talk about [MAiD]. I don't know, that's the message I carried after second year: don't you ever!" Another participant repeatedly expressed her concern for the legal ramifications of speaking to patients about MAiD, including the possibility of losing her nursing license. 
I just never really thought about it before I researched it in my fourth year and realized that there are a lot of grey areas and there's a lot of things that nurses cannot say and you can be in big trouble and get your license taken away.

Included in student concerns was the challenge of knowing when it is okay to broach the subject of MAiD with a patient, particularly in circumstances when a patient does not explicitly use the language "medical assistance in dying".

We're not allowed to suggest someone [should consider] MAiD, but at what point can either a nurse, or a nursing student, say that this person has requested MAiD because of such and such a statement? Because they really need to say a certain phrase to unlock the door, which then opens up into a whole variety of options. But if that person doesn't say those key words or kind of dances around the subject but doesn't even know that language exists, how as a nursing student or as a nurse can you work around that?

\section{Theme 2: Honouring Patient Autonomy}

"I feel like in MAiD, you're often enacting the highest level of autonomy that you can, in any decision of your life" (a student participant).

The importance of patient autonomy in decision-making was perhaps the strongest theme found across all interviews, including when participants described their reasons for supporting MAiD. This theme is discussed as two subthemes: The nurse as advocate, not judge and MAiD as "normal" nursing.

The nurse as advocate, not judge. Several students spoke of their professional responsibility to facilitate autonomous decisions, rather than pass judgement on these decisions. Facilitating patient autonomy was repeatedly expressed as outweighing the importance of students' own beliefs, with several participants emphasizing that nursing required them to put aside their own beliefs in order to provide appropriate and compassionate care. "What my beliefs are in this moment doesn't really matter, it's about you (the patient)," stated one participant. "It's your body, it's your life," shared another. One participant stated:

But I also feel that as a nurse, future nurse - or even as a person - it's not my place to judge people and their decisions and I'd want to do everything I could for that person. And if it means lots of time caring for that person and showing them, you know, compassion and love and whatever, then I'll do it. I would be there for them.

While another noted:

As nurses we take an oath to care for people no matter what our own beliefs and values are. So, if that is somebody else's belief and value, and that's what they want to do, then it is our responsibility to support them.

Despite still grappling with the personal, moral, and legal implications of MAiD, all participants expressed an overall support of the practice and wished to participate as careproviders for patients accessing a medically assisted death. Those who felt most challenged by MAiD on the basis of their belief system often referred to patient autonomy as the justification for this overriding support. One student shared:

I feel like I could definitely feel moral distress and I feel like I'm aiding in suicide in a way that I don't know if I would feel comfortable with... But you know, a lot of things in 
nursing don't align with your morals but you learn to handle it and deal with it, and this is a new thing that I want to respect people's decisions.

And another said:

I do come away from my belief systems because I think an individual shouldn't be expected to experience terrible pain. So yeah, it's a hard; it's a difficult decision I think. You know, to decide what really my perspective is... But I don't, I don't let my belief system interfere with my nursing care at all. I will support people who decide to do that. Absolutely. I would never share my own beliefs with them.

MAiD as "normal" nursing. When asked about whether or not they felt MAiD is within the "normal" scope of nursing, participants unanimously agreed that MAiD does not represent a significant departure from the heart of nursing care. In fact, one student described it as "right smack dab in the center [of nursing]". MAiD was viewed to be an extension of palliative and end-of-life care, and not an aberration, especially given "nurses deal with dying all the time". Additionally, students commonly spoke of the principles of autonomy and patient-centredness as guideposts to their nursing practice, including their support of MAiD. Many believed that a medically assisted death is just one more way nurses can enable patients to achieve the health goals most important to them. As one student explained:

I think a lot of people understand nursing as a process that preserves life... But nursing isn't only about just curing disease. It's about seeking what the patient needs and going from there. What is most salient to the patient? And how can you progress forward through what they deem most important to them?

One participant likened caring for a patient receiving MAiD to her experience of taking patients off a life-preserving ventilator in her previous role as a respiratory therapist. In both circumstances, she emphasized patient choice as imperative to ethical care, even when death is the outcome:

I've seen people at the end of their days, on the ventilator, and to have full faculty of their mind but then to have no control of the rest of their body. And then for somebody to tell you, no, no, you've got to stick around, that's just wrong!

Another student reflected on how her feelings around MAiD have changed. As a young adult, she was opposed to practices such as MAiD on the grounds of her religion. While still a person of Christian faith, she now feels that MAiD is justified because it supports individual choice: "I'm like, well no, this is [my] choice. It's your choice and I will support you in it. Because that is the most loving and compassionate thing that you can do for somebody, is to support them in their decisions."

\section{Theme 3: Personal-Professional Tensions}

While all participants expressed support for MAiD, participating in the practice provoked a complicated emotional experience for some. Tensions felt by the participants were illustrated in narratives about personal values, professional responsibilities, encounters they have had with MAiD, and uneasy anticipation of future encounters. Two predominant subthemes identified in these tensions were entangled emotions and intellect and surfacing hidden values.

Entangled emotions and intellect. Some participants expressed a contradiction between their intellectual understanding of MAiD, and the emotions that arose during the process of 
caring for a patient considering or receiving MAiD. Feelings of discomfort, unease, and ambiguity were expressed alongside a competing narrative of supporting MAiD on a logical level. One participant described these persona-professional tensions as a "heart versus brain thing". On her first contact with a patient who was a candidate for MAiD, she discovered an uneasiness that she had not been expecting. She attributed her internal conflict to her religious upbringing, which she no longer actively practices. She said:

I learned that I have a few hang-ups about MAiD that I didn't realize I had... like logically, I have no problem with it... but when it comes to the actual MAiD I found that it was... a heart vs. brain thing and my heart was like, oh something doesn't feel quite right. I just felt a little uneasy about it and I didn't quite know why because I was all for it.

Another student recounted observing a patient receive MAiD. Despite being in support of the practice, she felt emotional discomfort at the time of the procedure:

I guess it's really hard to separate my own belief system at that point. Again, not that I would ever let that interfere with that process, professionally, but while watching somebody take their last breath, it's hard to not go to your innermost emotions.

The emotional turmoil that a student experienced or anticipated when caring for a patient receiving MAiD was also dependent on the circumstance of that patient. Students associated the potential for moral distress with factors such as questioning if informed consent was possible in the patient's condition. Ensuring a patient had duly considered alternative options such as palliative care was also described as imperative to being able to stand behind the patient's decision to access a medically assisted death.

Surfacing hidden values. Students' unexpected emotions around the practice of MAiD triggered reflection on this source of tension. Some identified their current religious affiliation or religious upbringing being in direct conflict with MAiD, such as this student:

I think part of it was that I had a very religious upbringing which isn't really part of my life anymore, but it conflicted with that... and I think it lives like really deep down in my psyche. I didn't realize it was there until I was confronted with [Medical Assistance in Dying].

For the student above, the news that her patient postponed their scheduled MAiD elicited unexpected relief, which she felt to be an automatic and inappropriate response: "And I was like oh, I shouldn't feel relief, this is a professional relationship and it's her decision, and why do I have that gut reaction - to be like oh it's a good thing - and know I shouldn't feel like that."

\section{Theme 4: Students' Recommendations for Education}

Participants were asked to reflect on their sense of being prepared to participate in MAiD, including their BSN curriculum. Students who felt well prepared often referred to taking their own initiative, outside of mandatory readings, by pursuing projects and presentations on MAiD. Participants who held previous careers in health care as LPNs or respiratory therapy also felt these experiences made them less fearful to care for a patient accessing MAiD. All participants felt improvements could be made to their BSN education to strengthen their sense of preparedness. Concrete examples are presented in Table 1. 
Table 1

Participants'suggestions: educational preparation for MAiD

- Incorporate lectures and workshops facilitated by nurses and health professionals who have first-hand experience with MAiD

- Provide clear instruction on the roles and responsibilities of student nurses, RNs, and LPNs in MAiD

- Provide opportunities to clarify and work through feelings about MAiD and understand conscientious objection

- Use clinical simulation to role play speaking with a patient about MAiD and carrying out the role of the nurse during a MAiD death

\section{Discussion and Implications for Practice}

Findings in this early study point to the complex nature of caring for a patient receiving MAiD. Participants demonstrated awareness of the delicate nature of end-of-life care and reflected on the personal process of determining their own beliefs. For some students, the process of clarifying values involved grappling with the morality of being implicated in hastening death. Current religious affiliation or religious upbringing intensified the uneasiness of some participants, a finding that is echoed in research from around the world. Margalith, Musgrave, and Goldschmidt (2003) identified a strong association between degree of religiosity and support of Physician-Assisted Suicide (PAD) in Israeli nursing students. In this study, the majority of secular students supported PAD, while those who identified as religious were predominantly opposed to it. Similarly, a study of Muslim nursing students in Iran found 64\% were in strong opposition to active euthanasia (defined as care providers "taking active steps to terminate the patient's life") and the majority of the respondents agreed that their religious affiliation was a strong influence in their attitude (Hosseinzadeh \& Rafiei, 2017). Notwithstanding the diverse cultural considerations of these studies, what differed in the current Canadian study was an overriding support for MAiD from all students, even where tensions and ambiguity arose on the basis of religious beliefs. This difference may reflect disparities between cultural and geopolitical contexts, the recent legal status of MAiD in Canada, as well as a trend of liberal attitudes toward medically-assisted dying in Canadian society.

These findings point to participants' expressed appreciation for having exposure to MAiD in their nursing program, as this allowed them to work through their unease before taking full responsibility for patients. Similarly, Edo-Gual et al. (2014) identified that nursing students valued opportunities to witness patients dying, as it allowed them to temper their own reaction to death. Providing space for students to vent their feelings was seen to further mitigate the lasting emotional burden of the experience (Edo-Gual et al., 2014). Although hastening death through assisted dying is a different context, findings from our study support students' valuing of both opportunities to work with dying patients who choose MAiD and engaging in reflective activities about MAiD prior to and after encountering it in practice.

Participants conveyed a lack of understanding of their roles and responsibilities as students and future nurses with MAiD, as well as fear of the legal consequences of their current participation. Nurses in a Canadian study by Oliphant (2017) also expressed concern about the 
restrictions placed on nurses to speak with their patients about MAiD. However, it was not fear of losing their license, but rather the potential these restrictions had to compromise the nursepatient therapeutic relationship, which they saw as "intrinsically" conversational. In this study, the novelty of MAiD in Canada is no doubt a factor in role confusion, including a lack of explicit guidelines for students in the health authority at the time of the study.

Several participants expressed the need to take the initiative in learning about MAiD, suggesting the importance of implementing more formalized MAiD curricula for BSN students. Findings suggest both students and educators can be better informed about the evolving legislation and guidelines about MAiD. Specifically, students suggested simulation (including conversations with patients), guest lecturers, and reflective practices, which are supported by research as beneficial approaches. Simulation has been proven to be an effective pedagogical approach to competency development in end-of-life care (Gannon et al., 2017; Leighton \& Dubas, 2009). In addition, seminars with nurses or physicians who have directly participated in MAiD provide insight for students into the logistics of the procedure, as well as the emotional depth of assisting in an individual's death. Ensuring students and educators are knowledgeable about their professional organizations' guidelines such as the Canadian Nurses' Association (CNA) (2017), provincial regulatory standards, and institutional policies, will help clarify misunderstandings and role confusion.

For many participants, honouring patient autonomy was situated at the heart of MAiD care. This finding reflects an ideological shift in North American health care that has endorsed patient-centredness and autonomy over paternalism (Joffe, Manocchia, Weeks, \& Cleary, 2003; Murphy, 2008; Sandman \& Munthe, 2009). Participants in this study received education that emphasized the Standards of Practice outlined by the Provincial regulatory body (College of Registered Nurses of British Columbia [CRNBC], (2012), as well as the Canadian Nurses Association's Code of Ethics (CNA, 2017). Tenets of both these documents include standards of promoting autonomous, informed decision-making, practicing non-judgment, and identifying and resolving the effects of one's own beliefs on client care. As a key bioethical principle and mainstay of human rights debates, the concept of fostering individuals' autonomy is well engrained in the professional responsibilities of nurses in Canada and BSN curricula.

Student nurses are bound to confront moral challenges in care, particularly as they come to grips with the limitations of their inexperience and witness the dissonance between nursing ideals and practical realities. MAiD presents yet another situation where students must engage their ethical decision making in order to provide compassionate and safe care. Findings from this study demonstrate how abiding by the principle of patient self-determination helped participants to navigate their encounters with MAiD, particularly in the face of their own feelings and moral conflict. This type of principle-based reasoning has been documented by Ham (2004), who found nursing students demonstrated strong principled thinking in ethical dilemmas, even surpassing the moral integrity of their experienced nurse counterparts. This suggests that nursing students can effectively utilize ethical frameworks presented to them through education and benefit from opportunities to continue practical application of these skills in class and clinical settings.

This research supports strong, consistent MAiD education for nurses and nurse educators working on clinical units in order to enhance nurse-student mentorship in this field. Furthermore, it calls for further research on this topic in the Canadian context. Inquiry into students' experiences in other Canadian nursing programs, and later if changes to the legislation occur, 
would ensure greater diversity and capture evolving perspectives as MAiD becomes established and normalized.

\section{Limitations}

This study was carried out using convenience sampling. It includes the perspectives of students from only one university, and as such likely reflects the particular educational, political, and social climate in which these students live. The age of the participants is high (mean=35 years) and should be considered when interpreting students' perceptions of MAiD. While qualitative research does not seek generalizability, it is worth keeping these factors in mind when applying results to other contexts.

\section{Conclusion}

As a recently legalized practice in Canada, Medical Assistance in Dying represents a dynamic intersection of ethical, legal, moral, and personal considerations. For nursing students in this study, encounters with MAiD spawned a process of reflection and values clarification, including the emergence of discrepancies between intellectual support of MAiD and emotional unease felt in practice. Findings suggest participants were ill-equipped to identify their roles and responsibilities in the provision of MAiD, and perceived RNs were equally unprepared. Despite role confusion, students identified an underlying dedication to supporting patient autonomy and unanimous support for MAiD. Recommendations for educators include incorporating seminars on medically assisted death (facilitated by health care professionals with first-hand experience) and simulation and role-play. Further research is required to understand the geographical range and evolution of attitudes and experiences of Canadian nursing students with MAiD. 


\section{References}

Attaran, A. (2015). Unanimity on death with dignity - Legalizing physician-assisted dying in Canada. The New England Journal of Medicine, 372(22), 2080-2082. https://doi.org/10.1056/nejmp1502442

Bill C-14: An act to amend the criminal code and to make related amendments to other acts (medical assistance in dying). (2016). Ottawa, ON: Ministry of Justice. Retrieved from http://www.parl.gc.ca/content/hoc/Bills/421/Government/C-14/C-14_4/C-14_4.PDF

Braun, V., \& Clarke, V. (2006). Using thematic analysis in psychology. Qualitative Research in Psychology, 3(2), 77-101. https://doi.org/10.1191/1478088706qp063oa

Canadian Nurses Association [CNA]. (2017). CNA: Code of ethics for registered nurses. Retrieved from https://www.rnantnu.ca/professional-practice/code-ethics

College of Registered Nurses of British Columbia [CRNBC]. (2012). Professional Standards for Registered Nurses and Nurse Practitioners. Retrieved from https://www.crnbc.ca/Standards/Lists/StandardResources/128ProfessionalStandards.pdf

Cooper, J., \& Barnett, M. (2005). Aspects of caring for dying patients which cause anxiety to first year student nurses. International Journal of Palliative Nursing, 11(8), 423-430. https://doi.org/10.12968/ijpn.2005.11.8.19611

Edo-Gual, M., Tomás-Sábado, J., Bardallo-Porras, D., \& Monforte-Royo, C. (2014). The impact of death and dying on nursing students: An explanatory model. Journal of Clinical Nursing, 23(23-24), 3501-3512. https://doi.org/10.1111/jocn.12602

Gannon, J., Motycka, C., Egelund, E., Kraemer, D. F., Smith, W. T., \& Solomon, K. (2017). Teaching end-of-life care using interprofessional simulation. Journal of Nursing Education, 56(4), 205-210. https://doi.org/10.3928/01484834-20170323-03

Garrino, L., Contratto, C., Massariello, P., \& Dimonte, V. (2017). Caring for dying patient and their families. Journal of Palliative Care, 32(3-4), 127-133. https://doi.org/10.1177/0825859717745169

Ham, K. (2004). Principled thinking: A comparison of nursing students and experienced nurses. Journal of Continuing Education in Nursing, 35(2), 66-73. https://doi.org/10.3928/0022-0124-20040301-08

Hosseinzadeh, K., \& Rafiei, H. (2017). Nursing student attitudes toward euthanasia: A crosssectional study. Nursing Ethics. https://doi.org/10.1177/0969733017718393

Joffe, S., Manocchia, M., Weeks, J. C., \& Cleary, P. D. (2003). What do patients value in their hospital care? An empirical perspective on autonomy centred bioethics. Journal of Medical Ethics, 29(2), 103-108. https://doi.org/10.1136/jme.29.2.103

Leighton, K., \& Dubas, J. (2009). Simulated death. Clinical Simulation in Nursing, 5(6), $223-$ 230. https://doi.org/10.1016/j.ecns.2009.04.093

Li, M., Watt, S., Escaf, M., Gardam, M., Heesters, A., O'Leary, G., \& Rodin, G. (2017). Medical assistance in dying - implementing a hospital-based program in Canada. The New England Journal of Medicine, 376(21), 2082-2088. https://doi.org/10.1056/nejmms1700606 
Margalith, I., Musgrave, C. F., \& Goldschmidt, L. (2003). Physician-assisted dying: Are education and religious beliefs related to nursing students' attitudes? The Journal of Nursing Education, 42(2), 91-96. https://doi.org/10.3928/0148-4834-20030201-10

Murphy, J. F. A. (2008). Paternalism or partnership: Clinical practice guidelines and patient preferences. Irish Medical Journal, 101(8), 232.

Oliphant, A. (2017). "If not me, then who?" The narratives of Medical Aid in Dying (MAiD) providers and supporters around their professional identity and role in MAiD. Master's thesis (McMaster University, Canada). Retrieved from http://hdl.handle.net/11375/22146

Österlind, J., Prahl, C., Westin, L., Strang, S., Bergh, I., Henoch, I., ... Ek, K. (2016). Nursing students' perceptions of caring for dying people, after one year in nursing school. Nurse Education Today, 41, 12-16. https://doi.org/10.1016/j.nedt.2016.03.016

Ranse, K., Ranse, J., \& Pelkowitz, M. (2018). Third-year nursing students' lived experience of caring for the dying: A hermeneutic phenomenological approach. Contemporary Nurse, 54(2), 160-170. https://doi.org/10.1080/10376178.2018.1461572

Riessman, C. (2008). Narrative Methods for the Human Sciences. Thousand Oaks, CA: Sage.

Sampaio, A. V., Comassetto, I., Mancussi e Faro, A. C., Dos Santos, R. M., \& Silva Monteiro, F. (2015). The experience of nursing students facing death and dying. Investigación y Educación En Enfermería, 33(2), 305-314. https://doi.org/10.17533/udea.iee.v33n2a13

Sandman L. \& Munthe C. (2009) Shared decision mailing, paternalism and patient choice. Health Care Analysis, 18(1), 60-84. https://doi.org/10.1007/s10728-008-0108-6

Singh, S. C. (2012). Euthanasia and assisted suicide: Revisiting the sanctity of life principle. Journal of the Indian Law Institute, 54(2), 196-231. 